\title{
The Doctrinal Significance of General Prevention in Criminal Law
}

\author{
Cong Ma \\ Law School \\ Zhejiang University of Finance \& Economics \\ Hangzhou Zhejiang Province 310018 P. R. China \\ dr.macong@gmail.com
}

\begin{abstract}
The penal purpose of general prevention is a new doctrine in criminal law theory. The modern concept of general prevention includes four aspects: pursuit of such effects of general deterrence, social learning, loyalty to law and satisfaction. General prevention can be justified criminal legislation except punishment of death penalty and it is regarded as the minimum requirement when distributing punishment. General prevention is in a central status in criminal law theory and practice, which means it is able to be the core of penal theory and logical starting point of crime constitution system theory.
\end{abstract}

Keywords-doctrinal significance; general prevention; shaping loyalty; central status ;staring point

\section{INTRODUCTION}

The penal purpose of general prevention is a fundamental issue that occupies a very important position in criminal law theory and practice, and meanwhile, in different historical periods and different countries or areas, it is always a controversial theme. Through the review of studies of penal purpose of general prevention all over the world, it discovers that among this field, there are still some important and valuable issues that have been unsettled, which are the concept of general prevention, the logical positions and functions of that in different stages of penal implementation practice, and its systematical position and significance in the theories of penalty and constitution of crime.

Raising and then solving these issues scientifically and reasonably is not only beneficial to general prevention to play an instructive role in the explanation of certain legislations in criminal field, then promoting the degree of definiteness of criminal law provisions and explanations, but also to general prevention to play a measure and examination role in different kinds of theoretical viewpoints, then enhancing the consistency of systematization and further development of criminal law theory. And more importantly, raising and solving of these issues helps to promote the implementation of general prevention sufficiently among both the theoretical and practical fields of criminal law, to reshape a clear and definite social perception of right and wrong; to develop citizens' conscientious and law-abiding habituation, and then shape citizens' loyalty to law; on the basis, it helps to advance the level of rule of law effectively in China, and finally achieve the task of modernization and rationalization of national governance and social management

\section{THE HistoricAL AND MODERN CONCEPT OF GENERAL PREVENTION}

\section{A. Trends in the Historical Concept of General Prevention}

The penal purpose of general prevention is not only a developing concept, but also a normative concept in the meaning of criminal law. From the historical perspective, the concept of general prevention changes continually with the social development. Now both in western countries and our country, the concept of general prevention is developing in the direction of rationalization and accuracy, and furthermore, the connotation of general prevention is enlarging.

\section{B. Modern Features of General Prevention}

In the meaning of modern criminal law, the penal purpose of general prevention should be a normative concept, therefore, it refers to that the influences and effects to the general society citizens which the state wishes to achieve with the application of penalties. The purpose of general prevention includes not only the purpose of general deterrence, which is based on the psychological coercion effect that the threat of penalty produces, but also includes the purpose of positive general prevention, which sets the justice, rationality and forgiveness of criminal law itself as the prerequisites of the goal's achievement, and then, this positive general prevention includes three aspects, which are learning effect, loyal effect and satisfied effect. Now, to positive general prevention is being paid more and more attention, and is becoming the central element of the purpose gradually.

\section{The Significance of Modern Concept of General Prevention}

The historical change and the scientific definition of general prevention concept demonstrates that if this purpose could be of full fulfillment, then the features of definiteness, social rightness and forgiveness for criminal law itself must be emphasized. Therefore, the development of general prevention concept, especially the introduction of positive general prevention, promotes the level of rationalization and legalization of criminal law, and meanwhile, it overcomes the weaknesses that general prevention has such as absence of limitation, improper distribution of punishment, and the possibility of treating citizens as means, avoids or reduces the 
criticisms of general prevention, and finally makes this concept itself become more and more scientific and accurate.

\section{THE POSITION AND FUNCTIONS OF GENERAL}

\section{PREVENTION IN IMPLEMENTATION OF CRIMINAL LAW}

The position and the function of general prevention in the practical process of infliction and operation of criminal punishment, which means the stage of institutional design, application and implementation of punishment, is not the same. How to distribute and arrange the different elements of penal purposes reasonably in different stages of infliction and operation of punishment, is always a controversial issue. This article insists that the whole implementing process of criminal law should be divided into three stages: which are the legislation, sentence and execution, therefore the discussion will be as follows:

\section{A. The Dominant Position and Main Justification of Criminal Legislation}

According to the practical situation of criminal law in our country, general prevention could be the justification of all the institutional designs except death penalty, thus, in this stage, general prevention is exposed to a dominant position. The justification of death penalty should be purpose of just retribution, and in the limitation of retributive purpose, general prevention could get the meaning of existence.

\section{B. The Subsidiary Position and Minimum Requirement of Sentencing}

In the stage of application of punishment, retribution becomes the maximum limitation, general prevention is regarded as the minimum requirement, and special prevention turns into the regulator, thus, in this stage, general prevention is exposed to a subsidiary position. The subsidiary position has its own independent significance: it sets the minimum requirement of punishment for certain special criminal cases, it takes up the task of justifying the application of punishment independently when the purpose of special prevention fails or is of absence; besides, general prevention supplies a general criteria of punishment for justice judgment and the mode of citizen's behaviors, then it helps to achieve the task of transparency and precision of criminal law.

\section{The Affiliated Position in Execution of Punishment}

In the stage of implementation of punishment, the existence and pursuit of purpose of general prevention, especially the positive general prevention, could be allowed in the narrow framework of special prevention and retribution.

\section{The Central Position of General Prevention in CONSTRUCTION OF PENAL THEORY}

In the construction and development of theories of penalty, general prevention could become the theoretical core. The requirement and influence of general prevention must be considered not only in the theory of institutional design of punishment but the conviction and sentence.
A. The Evaluative Function of General Prevention in Theory of Institutional Design of Punishment

In theory of institutional design of punishment, general prevention not only supplies justification for theory of arrangement of types of punishment and application of them in special situations, but also supplies the inspection standard and development space for these theories, then accordingly, drives the further development of penal theories in the direction accordance with the requirement of general prevention, sequentially, through influence of penal theories to the making and institution of operation of penalty, the whole level of definiteness, accuracy and justice among the institutional design and special application of punishment could be enhanced dramatically.

\section{B. The Special Roles of General Prevention in Principle of Conviction and Sentencing}

In the principle of penal application, general prevention also plays a very important role.

In certain special and hard cases, the amount of punishment could be considered firstly according to general prevention, and then based on the choice of amount of punishment, the accusation can be determined. Through the way of thinking of penalty determining the accusation reversed, which is guided by the purpose of general prevention, the goal of proportionality and justice could be achieved.

In the sentence theory, the accurate rules, procedures, methods and institutional protections of sentence must be established and applied, which is the fundamental requirements of definiteness and justice that could be regards as internal standards of general prevention.

\section{The Logical Starting Point Position of General PREVENTION IN SYSTEM OF CRIME CONSTRUCTION}

In the construction and development of theories of crime constitution, the general prevention-oriented penal purposes and criminal policy can be communicated, coordinated and combined with the theory of crime construction very well.

To construct and develop the constitution of crime based on the purpose of general prevention, is not only the double claims of social development reality and the system of criminal law, but the reflections of the double tasks of criminal law, which include crime prevention and protection of citizens' living space for freedom.

\section{A. The Significant Role of Definiteness of General \\ Prevention in Behavior-Constitution Aspect of Crime Construction}

In the constitution of crime field, the requirement of definiteness that general prevention puts forward performs an important role. As to the criteria of definiteness of constitution of crime, it is generally considered that if one can understand the protective end of a provision of criminal law clearly, and this provision can also provide a limitation to any kind of arbitrary extensive interpretation, then, this provision meet the definiteness demand. Except the definiteness demand and emphases on the criteria and limitation, among some specific 
issues in this field, such as the foundation of duty of care, the basic rule of mistake of law and the normalization of causation, the social rightness and forgiveness requirement should also be taken into account, which is valuable and significant to encouraging citizens to abide criminal law and shape loyalty to criminal law.

\section{B. The Social Rightness Requirement of General Prevention in the Aspect of Wrongfulness of Crime Construction}

In the wrongfulness field, the basic function of wrongfulness is decriminalization but not crimination anymore. The foundation of wrongfulness should be the social rightness and justice, and this foundation is of great significance to consolidate the social perception of right and wrong, maintain social solidarity, and shape loyalty to law.

\section{The Necessity Requirement of General Prevention in the Aspect of Blameworthy of Crime Construction}

In the blameworthy field, the concept of culpability has been started to extend its contents and becomes more and more functional, now, the concept of criminal blameworthy has been formed, which includes the culpability and the necessity of prevention. In the developing process of criminal law, the differentiation of justification and excuse is of great importance to clarify the social perception of right and wrong, encourage and cultivate the habituation of law abiding, and establish the moral reputation and authority. It is a major sign of the requirement of social forgiveness in criminal law that general prevention claims to that the excuse is allowed and regarded as the justification of decriminalization

\section{A NEW DOCTRINE AND ITS SigNIFICANCE IN CRIMINAL LAW}

To sum up, through the study of concept of general prevention and its systematical position and function, it concludes that, the penal purpose of general prevention is able to be the theoretical core and logical start point of criminal law.

Due to the important position, general prevention can take up the theoretical task of justifying the punishment and criminal law, and it is here that from the perspective of justification of criminal law and also at the level of that, it could be considered that the penal purpose of general prevention has doctrinal significance of criminal law.

Furthermore, this doctrinal significance of general prevention, helps to improve the degree of definiteness of criminal law, and to make criminal law accord with the claims of social rightness and forgiveness to a higher degree, then on the basis, this significance is of value to consolidate the citizens' respect and reliance on criminal law, and also to cultivate the habituation of law-abiding and finally shape loyalty to criminal law.

\section{REFERENCES}

[1] P. H. Robinson, Distributive Principles of Criminal Law: Who Should be Punished How Much. London: Oxford, 2008, pp.1-7.

[2] A. Duff, Punishment. Dartmouth: Ashgate Publishing, 1993, pp. 35-43.

[3] J. Andenaes , “The Morality of Deterrence,” 37 U. Chi. L. Rev. Chicago, vol. 37, pp.649-664, Summer 1970.

[4] C. Roxin, Kriminalpolitik und Strafrechtssystem. Berlin: Walter de Gruyter, 1973, pp.23-41.

[5] C. Roxin, Strafrecht Allgemeiner Tell Band 1: Grundlagen Aufbau der Verbrechenslehre. München: C. H. Beck, 1997, pp.51-75. 